\title{
Principal instructional leadership and secondary school performance
}

\author{
LINDA BENDIKSON, VIVIANE ROBINSON and JOHN HATTIE
}

\section{KEY POINTS}

- $\quad$ Principal instructional leadership can be direct (focused on improving teaching) or indirect (focused on creating the conditions for optimal teaching and learning).

- In secondary schools, principals are more likely to focus on indirect instructional leadership than they are in primary schools, because middle leaders such as heads of department take on much of the direct instructional leadership.

- In the study reported in this article, principals in both higher and lower performing schools were rated higher for frequency of both direct and indirect leadership behaviours than principals of mid-performing schools.

- However, principals in schools that were improving in performance (regardless of level) were displaying more frequent direct leadership behaviours than principals from the other schools.

- This may reflect the need for effective principals to respond appropriately to the conditions at their specific school. 
A lot of emphasis is currently placed on the need for principals to be instructional leaders or leaders of learning. In the study of the instructional leadership of secondary principals reported in this article, the authors argue that instructional leadership can be both direct and indirect. Direct instructional leadership is focused on the quality of teacher practice itself, whereas indirect instructional leadership creates the conditions for good teaching. Indirect instructional leadership is particularly important for secondary principals because much of the direct leadership is carried out by deputies and heads of department. The authors found that, when looking at the achievement results of the school as a whole, different instructional leadership behaviours predicted high performance and improvement.

A lot of emphasis is currently placed on the need for principals to be instructional leaders or leaders of learning, primarily because this type of leadership has a stronger impact on student outcomes than other types of leadership. The more focused the school's leadership is on instruction, the more effective the school will be in adding value to student outcomes (Robinson, Lloyd, $\&$ Rowe, 2008). It is not clear, however, whether this means the same thing for secondary principals as it does for primary principals, or whether it means the same for principals in schools that are already high performing and those that have much room to improve.

\section{Differences between primary and}

\section{secondary schools}

In general, secondary schools differ from primary in three important ways: their size, their organisation into subject departments and the age of their students. The typically larger size of secondary schools brings additional layers of hierarchy. This more elaborate hierarchy means that a greater proportion of secondary principals' interactions, relative to those of their primary counterparts, are likely to be with staff who have responsibility for a group of classroom teachers rather than with classroom teachers themselves.

These structural differences between secondary and primary schools do not mean that secondary principals do not or should not visit classrooms, or give feedback to individual teachers. It does mean, however, that since there are middle leaders who have specific responsibilities in these areas, secondary principals are less likely to engage in this type of direct instructional leadership than their primary counterparts. Given the delegation of responsibility for teaching and the curriculum to middle leaders, secondary principals' instructional leadership is likely to be exercised more indirectly through oversight of those who have delegated responsibility for the quality of classroom teaching. Very little is known about how this oversight occurs, including the extent to which principals inquire into what their middle leaders know about the impact of teaching on the students for whom they are responsible.

In addition to such oversight, secondary principals exercise a second form of indirect instructional leadership by leading the process of creating norms and routines that ensure quality teaching and learning across the whole school. The principal's instructional leadership is exercised by organising and managing the school-everything from student management, timetables and resource and staffing allocation to professional development policies. Principals' decisions about these policies and routines set the conditions for what happens in classrooms and corridors between students and teachers. These managerial functions are the bedrock of principal instructional leadership in secondary schools.

Departmentalisation of secondary schools is another major influence on the role of the principal. Heads of department are the direct instructional leaders for their departments because they attend to the details of curriculum delivery in their subjects (Siskin, 1991, 1994). The secondary principal's role is to facilitate and develop the instructional leadership of these middle leaders (Firestone \& Herriott, 1982; Foster, 2004; Kleine-Kracht, 1993). 
The nature of adolescents is another factor that impacts on the secondary principal's role. The age of the students brings particular challenges frequently not experienced in primary schools and results in the principal often being involved in matters concerning individual students with major challenges.

In summary, it may be useful in a secondary school context to distinguish between the direct and indirect instructional leadership of the principal. It is this distinction that we are particularly interested in exploring in this article.

\section{The distinction between direct and indirect instructional leadership}

In the study that we report on here, instructional leadership of secondary principals is conceptualised as both direct and indirect. Direct instructional leadership is focused on the quality of teacher practice, including the quality of the curriculum, teaching and assessment, and the quality of teacher inquiry and teacher learning. Indirect instructional leadership creates the conditions for good teaching and teacher learning by ensuring that school policies, routines, resourcing and other management decisions support and require high-quality learning, teaching and teacher learning (Kleine-Kracht, 1993).

We want to make clear that not all management behaviour in a school counts as indirect instructional leadership. Some managerial functions may be no more than acts that maintain an unsatisfactory status quo. Examples include lengthy meetings that are taken up with administrative matters and leadership that makes decisions about resource allocation, teacher appraisal, classroom observations, homework or the use of computers without explicit reference to their impact on the quality of teaching and learning. These behaviours do not count as indirect instructional leadership. The effective principal manages the environment to optimise learning (indirect instructional leadership) and provides guidance and support for other school leaders or teachers to improve the quality of instruction and the achievement of all students (direct instructional leadership).

The emphasis on academic press or the press for the achievement of all students, we argue, is the defining factor that can make all of these behaviours instructional leadership.

The five leadership dimensions derived from Robinson and colleagues' (2008) meta-analyses of the impact of various leadership practices on studentsgoal setting, ensuring quality teaching, leading teacher learning, strategic resourcing and ensuring a safe and orderly environment - include both direct and indirect instructional leadership. Leadership through goal setting, ensuring teaching quality and leading teacher learning are all included in our concept of direct instructional leadership. The two remaining dimensions (strategic resourcing and ensuring a safe and orderly environment) are indirect and, while not as strong in their effects as the first three, are also important, for they create the environment for both staff and students that makes learning possible. These indirect forms can be educationally powerful if the principal's focus is unrelentingly on the press for achievement.

Our study was designed to identify these indirect as well as more direct instructional leadership practices by secondary school principals and to examine their impact on school performance and improvement. More specifically, we investigated which behaviours (direct or indirect) were most commonly performed by the principal and which were more likely to be performed by other members of the leadership team. We also investigated whether the extent of principals' direct and indirect instructional leadership differed between higher, mid- and lower performing schools, and whether it differed between improving and nonimproving schools. Finally, we estimated the impact of principal instructional leadership in secondary schools on school performance levels.

\section{Research participants and measures}

Our sample was drawn from the 102 schools that taught secondary-age students in the central North Island. Of those 102 schools, 79 had the traditional secondary configuration of Years 7 or 9 to 13. Of the 79 in the possible sample, 29 schools (37 percent) returned consent forms and useable questionnaires. The questionnaire on principal leadership was completed by 651 teachers in these 29 schools.

The relatively low response rate means that caution is needed in interpreting the results. It was not possible to secure a higher response rate because the lead writer was a senior manager in the Ministry of Education at the time the research was carried out, and one of the conditions of gaining ethical approval for the study was that there would be no follow-up of the initial invitation to participate. The resulting school sample was both higher performing and higher decile than the wider school population. Nevertheless, this research allows further insight into some specific aspects of principal instructional leadership in secondary schools that can be considered with other similar research from a variety of countries. 


\section{Measure of school performance and improvement}

Publicly available student achievement data (from the National Certificate of Educational Achievement-NCEA) were used to categorise all 102 schools in the central North Island by performance level. A method of aggregating different NCEA indicators was developed in order to categorise schools as higher, mid- or lower performing (see Bendikson, Hattie, \& Robinson, 2011). A second set of indicators was used to identify schools that were improving regardless of their present level of performance, because the aim of principal leadership is, or ought to be, to improve student outcomes (Elmore, 2004; Fullan, Cuttress, \& Kilcher, 2005). These two indicators assessed the level and consistency of school performance over a 4-year period. In summary, all 102 schools were classified according to their level of performance, and the top quartile of schools on the improvement indicators were also categorised as improving schools. The relationship between school performance and improvement and the extent and type of principal instructional leadership was then assessed.

\section{Measures of principal instructional}

\section{leadership}

Teachers completed a 60-item survey about the frequency of principal leadership practices and their views on school culture (the latter is not reported here). Twenty items related specifically to the frequency of principal instructional leadership, and a further 10 related to the roles taken by other positional leaders in the school, such as heads of department and deputies. Each item was rated on a 5-point frequency scale in which the scale extremes were described as almost never (1) to almost always (5). In addition to the five dimensions used by Robinson and colleagues to categorise instructional leadership, two further dimensions (Solving complex problems and Developing a sense of collective responsibility) were rated as there is some evidence from studies in secondary contexts (Heck \& Mayor, 1993; Lee \& Smith, 1996) that these leadership behaviours are educationally powerful. Table 1 sets out the instructional leadership dimensions we used in our study.

TABLE 1 INSTRUCTIONAL LEADERSHIP DIMENSIONS

\begin{tabular}{|l|l|}
\hline Direct instructional leadership dimensions & $\begin{array}{l}\text { Indirect instructional } \\
\text { leadership dimensions }\end{array}$ \\
\hline Setting goals & $\begin{array}{l}\text { Ensuring a safe and orderly } \\
\text { environment }\end{array}$ \\
\hline Ensuring quality teaching & Resourcing strategically \\
\hline Professional development & Solving complex problems \\
\hline Developing a sense of collective responsibility & \\
\hline
\end{tabular}

\section{Findings}

\section{What behaviours (direct or indirect) did principals most commonly display?}

In our earlier discussion of differences between primary and secondary schools we argued that principals in a secondary school environment were most likely to use indirect instructional leadership behaviours as they are the facilitators of the direct instructional leadership of others (for example, heads of department). An analysis of the means of the principal scores for each dimension supports this view (Table 2). The most common instructional leadership behaviour of principals was Setting goals (a direct behaviour), followed by Ensuring a safe and orderly environment, Resourcing strategically and Solving complex problems (indirect behaviours). The least used were Developing a sense of collective responsibility and Ensuring quality teaching (direct behaviours).

TABLE 2 MEANS OF PRINCIPAL INSTRUCTIONAL LEADERSHIP DIMENSIONS $(N=651)$

\begin{tabular}{lll} 
& Mean & $\begin{array}{l}\text { Standard } \\
\text { deviation (SD) }\end{array}$ \\
\hline Indirect dimensions & \\
Ensuring an orderly environment & 4.02 & 0.83 \\
Resourcing strategically & 3.97 & 0.77 \\
Solving complex problems & 3.86 & 0.98 \\
Average of indirect & 3.95 & \\
Direct dimensions & & \\
Setting goals & 4.07 & 0.72 \\
Professional development & 3.81 & 0.82 \\
Ensuring quality teaching & 3.52 & 0.85 \\
Developing collective responsibility & 3.43 & 0.89 \\
Average of direct & 3.70 & \\
\hline
\end{tabular}

Note: $5=$ almost always, $4=$ often, $3=$ sometimes, 2 = rarely, 1 = almost never.

\section{What instructional roles do the various leadership team members take?}

An analysis of roles showed that principals were heavily involved in setting goals and standards and recruiting teachers. They shared responsibility for maintaining an orderly environment with deputies, but professional development was largely the domain of deputies and heads of department. Heads of department took the lead role in Ensuring quality teaching activities, such as helping teachers with data and carrying out classroom observations. Thus, as anticipated, the direct instructional leadership roles were largely carried out by deputies and heads of department, with the exception of goal and standard setting. 


\section{Differences between higher, mid- and lower performing schools}

An analysis of the means of the principal scores for each dimension by school performance level showed both some expected and some surprising results. While principals in higher performing schools $(n=7)$ were clearly rated higher on all dimensions than those in mid-performing schools $(n=17)$, principals in lower performing schools $(n=5)$ were usually rated higher than principals in midperforming schools. This pattern of results indicates that, in this sample at least, the five principals in the lower performing schools were perceived to be using more direct and indirect instructional leadership than the 17 principals of the mid-performing schools. Note that this result may be entirely due to sampling bias-the five principals of lower performing schools who agreed to participate were probably quite different in leadership confidence and possibly competence from those who did not agree to participate.

However, this result points to the usefulness of not just comparing lower and higher performing schools, as often occurs in this type of research. Effective principals in schools that are currently lower performing need to be displaying more instructional leadership than principals in schools that are already mid-performing, if they are to improve results.

\section{Differences between improving and other schools}

When improvement rather than performance was considered, a different story emerged. When the means for frequency of instructional leadership in improving schools were compared to those of the other schools, there was a pattern of higher means for the improving schools over others, but this time it was Setting goals along with Ensuring quality teaching and Developing a sense of collective responsibility where differences were most evident. These are all direct instructional leadership behaviours. The pattern that emerged was that, while direct instructional leadership might be the better predictor of improvement, indirect instructional leadership might be the best predictor of performance.

\section{What is the impact of principal instructional leadership?}

A multivariate analysis of variance (MANOVA) was conducted to test for differences between the three groups of schools across all instructional leadership dimensions taken as a whole. There were statistically significant differences between teachers' ratings of leadership dimensions across the three school performance categories. When higher, mid- and lower performing schools were compared (by ANOVA, analysis of variance), significant between-group differences were found for all dimensions with the exception of Professional development and Ensuring quality teaching. When just higher and mid-performing schools were compared, ${ }^{1}$ however, all dimensions were found to be significantly different. This means that teachers in higher performing schools rated principals as more frequently involved in instructional leadership than did their counterparts in mid-performing schools. The effect size for the comparison between instructional leadership in mid- and higher performing schools ranged from 0.17 for the principal's role in Professional development to 0.41 for Solving complex problems (see Table 3). Hattie (2009) suggests that $d=0.2$ should be considered a small effect, 0.4 a medium effect and 0.6 a large effect.

TABLE 3 EFFECT SIZES FOR INFLUENCE OF PRINCIPAL LEADERSHIP DIMENSIONS ON SCHOOL PERFORMANCE AND IMPROVEMENT

\begin{tabular}{lcc} 
& $\begin{array}{l}\text { Higher and } \\
\text { mid-performing } \\
\text { schools }+\end{array}$ & $\begin{array}{l}\text { Improving and } \\
\text { other schools } \\
++\end{array}$ \\
\hline $\begin{array}{l}\text { Indirect dimensions } \\
\text { Ensuring an orderly environment }\end{array}$ & $0.28^{* *}$ & 0.00 (NS) \\
Resourcing strategically & $0.36^{* * *}$ & 0.13 (NS) \\
Solving complex problems & $0.41^{* * *}$ & 0.11 (NS) \\
Direct dimensions & & \\
Setting goals & $0.31^{* * *}$ & $0.26^{* * *}$ \\
Professional development & $0.17^{*}$ & 0.04 (NS) \\
Ensuring quality teaching & $0.21^{*}$ & $0.19^{*}$ \\
$\begin{array}{l}\text { Developing collective } \\
\text { responsibility }\end{array}$ & $0.24^{* *}$ & $0.23^{*}$ \\
\hline
\end{tabular}

Notes: ${ }^{*} p<.05,{ }^{* *} p<.01,{ }^{* *} p<.001$, NS $=$ not significant.

The significance relates to the differences in means (reflected here as effect size differences). Tests of significance were carried out with both univariate ANOVAs and $t$-tests.

Effect sizes were calculated by the following formula: $(X 1-X 2) /((S D 1+S D 2) / 2)$.

+ A minimum of 178 teachers' scores from higher performing schools were compared to results reported by a minimum of 328 teachers in mid-performing schools. All results were analysed at the teacher level.

++ Teachers from improving schools, $n=269$; teachers from other schools, $n=338$.

\section{Discussion}

This research supports our view that secondary principals are more likely to engage in indirect than direct instructional leadership roles. It was not clear, however, if that would be true of principals in the most effective schools. In improving schools, use of the direct instructional leadership dimensions Ensuring quality teaching and Developing a sense of collective 
responsibility was more prevalent than in the other schools. High performance, on the other hand, tended to be characterised by use of these direct dimensions plus indirect instructional leadership, with the largest effects arising from Solving complex problems and Resourcing strategically. The direct dimension Setting goals had a consistently significant effect regardless of the groups of schools that were assessed.

These findings suggest that the nature of effective principal instructional leadership is dependent on the developmental stage of the school. Schools evolve and different leadership behaviour is likely to be required at different stages of development (Hallinger \& Murphy, 1987).

Often the concept of management is eschewed in favour of leadership, with managerial behaviours being dismissed as relatively unimportant. The results of this study suggest that we should not judge those managerial behaviours that support the learning environment (indirect instructional leadership) as less important than direct instructional leadership. Strong organisation, policies and routines underpin effective secondary learning environments (Elmore, 2007; Firestone \& Rosenblum, 1988), and principals have the responsibility to ensure these are in place. Managed poorly, structures and routines impede teacher practice, such as when meetings are time-consuming and unproductive or initiatives are not sustained through lack of support. But, managed well, structures and routines support teacher practice by, for example, ensuring students attend school every day and learning time is maximised.

In essence, we have argued that indirect instructional leadership is the bedrock of leadership in secondary schools. It is not just about "managing" as opposed to "leading". Instructional leadership by definition is strongly focused on the quality of instruction, but it attends to the underlying features of the school's organisational effectiveness (routines, good appointments, solving problems) as well as the quality of teaching. The importance of these underlying features should not be underestimated as mere "management" when the focus is firmly on improving learning. Without efficient routines and procedures, or good appointments, a principal is unlikely to be able to concentrate on the direct instructional leadership that this research has indicated is required for both improvement and high performance.

Overall, the indirect instructional leadership behaviours of principals (of which, problem solving appeared the most significant) were not only found to be most commonly used by all principals, but also to be most effective in maintaining high levels of performance (Table 3). The results of our research suggest that in higher performing schools, principals gain greatest effect by being not only good goal setters, but also strong problem solvers and strategic users of resources (for example, principals who hire quality staff and resource departments strategically), with the latter two dimensions being indirect instructional leadership.

Most schools identified here as improving were also categorised as already being mid-performing (Bendikson et al., 2011). The obvious unanswered question is: "What are the prerequisites for improvement?" Strong goal orientation appears to be one, as this is the most consistent dimension related to effective schools, both those that are higher performing and those that are improving. A sense of collective responsibility appears to be a second feature of schools that are able to improve-teachers have to believe that students can succeed and that disadvantages can be overcome. A third factor appears to be ensuring quality teaching by focusing on data and carefully monitoring outcomes. These data systems can be considered the artefacts of good instructional leadership and appear, in this sample at least, to be essential for gaining improvement in school performance results.

These findings point to the complexity of the principal leadership role. The success of the principal is conditional on their ability to work successfully in the conditions in which they find themselves. In a higher performing environment, a principal may find a depth of instructional leadership, in both the management team and wider teaching force, which enables them to focus on indirect instructional leadership (for example, ensuring an orderly environment, solving complex problems and resourcing strategically). But when principals are in schools where student outcomes need improving, that same depth of teacher leadership will probably not be found (or the school would be performing better). In that situation, the principal must take a more direct instructional leadership role. Developing the "appropriate conditions" (Hofman, Hofman, \& Guldemond, 2001) to either maintain a high level of performance or to gain improvement, is the complex and difficult role of the principal.

\section{Acknowledgement}

The authors are grateful to the anonymous reviewer for helpful comments on the reporting of the statistics.

\section{References}

Bendikson, L., Hattie, J., \& Robinson, V. M. J. (2011). Assessing the comparative performance of secondary schools. Journal of Educational Administration, 49(4), 433-449.

Elmore, R. (2004). School reform from the inside out: Policy, practice and performance. Cambridge: Harvard Education Press. 
Elmore, R. (2007). Educational improvement in Victoria. Retrieved 10 April 2012, from Department of Education and Early Childhood Development (State Government of Victoria): https://www.eduweb.vic.gov.au/edulibrary/public/ staffdev/schlead/Richard_Elmore-wps-v1-20070817.pdf

Firestone, W. A., \& Herriott, R. E. (1982). Prescriptions for effective elementary schools don't fit secondary schools. Educational Leadership, 40(3), 51-53.

Firestone, W. A., \& Rosenblum, S. (1988). Commitment in urban high schools. Educational Evaluation and Policy Analysis, 10(4), 285-299.

Foster, R. (2004). Leadership and secondary school improvement: Case studies of tensions and possibilities. International Journal of Leadership in Education, 8(1), 35-52.

Fullan, M., Cuttress, C., \& Kilcher, A. (2005). Eight forces for leaders of change. Journal of Staff Development, 26(4), 54-64.

Hallinger, P., \& Murphy, J. (1987). Instructional leadership in the school context. In W. Greenfield (Ed.), Instructional leadership: Concepts, issues and controversies (pp. 179-203). Boston, MA: Allyn \& Bacon.

Hattie, J. (2009). Visible learning: A synthesis of over 800 metaanalyses relating to achievement. London: Routledge.

Heck, R. H., \& Mayor, R. A. (1993). School characteristics, school academic indicators and student outcomes: Implications for policies to improve schools. Journal of Educational Policy, 8(2), 143-154.

Hofman, R. H., Hofman, W. H., \& Guldemond, H. (2001). The effectiveness of cohesive schools. International Journal of Leadership in Education, 4(2), 115-135.

Kleine-Kracht, P. (1993). Indirect instructional leadership: An administrator's choice. Education Administration Quarterly, 29(2), 187-212.

Lee, V. E., \& Smith, J. B. (1996). Collective responsibility for learning and its effects on gains in achievement for early secondary school students. American Journal of Education, 104(2), 103-147.

Robinson, V. M. J., Lloyd, C., \& Rowe, K. J. (2008). The impact of leadership on student outcomes: An analysis of the differential effects of leadership types. Education Administration Quarterly, 44, 635-674.
Siskin, L. S. (1991). Departments as different worlds: Subject subcultures in secondary schools. Educational Administration Quarterly, 27(2), 134-160.

Siskin, L. S. (1994). Realms of knowledge: Academic departments in secondary schools. London: Falmer Press.

\section{Note}

1 Using ANOVA and $t$-tests.

LINDA BENDIKSON is Director for the University of Auckland Centre for Educational Leadership. She was previously a teacher, principal and Regional Manager (Central North) for the Ministry of Education. Linda completed her PhD studies at the University of Auckland in 20II focusing on the educational management and leadership of secondary school principals.

Email: I.bendiksonळauckland.ac.nz

JOHN HATTIE is Director of the Melbourne Education Research Institute at the University of Melbourne Graduate School of Education and Honorary Professor at the University of Auckland. His research interests include measurement models and their applications to educational problems.

Email: jhattieœunimelb.edu.au

VIVIANE ROBINSON is a Distinguished Professor in the Faculty of Education at the University of Auckland and Academic Director of its Centre for Educational Leadership. She specialises in school improvement, leadership and the relationship between research and the improvement of practice.

Email: vmj.robinsonळauckland.ac.nz 